\title{
Translating Movement into Architectural Form
}

\section{Tim Ingleby ${ }^{1}\left[{ }^{10} \cdot\right.$ Stephen Orlando $^{1}$}

Accepted: 22 June 2021 / Published online: 9 July 2021

(c) The Author(s) 2021

\begin{abstract}
This work seeks to define original ways of creating architectonic forms using kinesiology studies. A series of methodologies are devised to record subjects in motion, with analogue and digital modelling techniques rigorously used independently and in combination to transpose these into sculptural figures with differing levels of formal fidelity and dimensional precision. Surface structures, and in particular thin shells, are found to have great potential for moving from abstract figures to structural forms. Such structures are traditionally problematic in terms of 'constructional energy', which has limited their usefulness and application. In response, the 'hanging cloth reversed' modelling technique devised by Heinz Isler is investigated to capitalise on the ambiguity between large-scale models and small structures. A construction method is devised that accords with the principles of structural art which, significantly, suggests that (small-span) shell structures could be liberated from the strictures of formwork to create economic, efficient and elegant minimal structures.
\end{abstract}

Keywords Modelling $\cdot$ Structural systems $\cdot$ Hanging cloth reversed method $\cdot$ Heinz Isler $\cdot$ Frei Otto $\cdot$ Structural art $\cdot$ Minimal surfaces $\cdot$ Kinesiology

\section{Introduction}

The representation of movement has long proven to be an influential artistic and technological provocation. Photography and film emerged pursuant to a desire to graphically record and communicate motion such that it could be understood with scientific precision. The motion studies of early photographic pioneers such as Eadweard Muybridge and Étienne-Jules Marey prefigured a looser, though equally

Tim Ingleby

timothyingleby@gmail.com; tim.ingleby@northumbria.ac.uk

Stephen Orlando

stephen@motionexposure.com

1 Department of Architecture, Northumbria University, Sutherland Building,

Newcastle upon Tyne NE1 8ST, UK 
expressive, language developed by Cubist and Futurist artists such as Duchamp and Bragaglia respectively.

Within these works, a tendency exists towards some sort of compression or 'flattening': the dynamic become static; three-dimensions (or four, if time is accepted as a dimension) are portrayed in two dimensions. Perhaps surprisingly then, there are few sculptural works exploring this territory. Of those that do, such as Boccioni's seminal Unique Forms of Continuity in Space of 1913, the dynamism of movement, though expertly portrayed, remains encumbered by a certain heaviness of expression.

Flow seeks to address this, the objective being to translate movement of people and objects into freestanding sculptural forms while maintaining the sense of fluidity and lightness suggested by their source material artist Stephen Orlando's time exposure artworks. Using LED lights with custom colour patterns and long-exposure photography, this technique reveals beautiful light trails created by the paths of dynamic subject matter, such as kayakers and canoeists. These light trails have not been artificially created in post-production and the photos are not composite images. For these photos, the camera's shutter is open for approximately 10-30 s, during which time the camera's sensor is collecting light. The photos capture a period of time as opposed to a single instant and the use of LED lights that change colour help convey this. Since the photos are taken in low light conditions, the only things that show up in them - that is, the only things emitting enough light to be picked up by the sensor - are either very bright, or stationary. The trees in the background are dark but stationary, so they get exposed in the photo. The LED lights are very bright so they emit a large amount of light for every point on their path and get exposed in the photo. The kayaker and the canoeist do not emit much light and since they're moving, they are never in the same spot long enough to register in the photo.

Giving the abstract figures described in Orlando's works three-dimensional form posed a number of interesting challenges. Modelling played an essential role in conceiving, defining and testing a series of responses to these challenges.

In seeking to reconcile the combination of artistic and technical demands, this work seeks to respond to the ideals of structural art: 'economy, efficiency and elegance' (Billington 1985: 5). The work of two structural artists in particular have been formative: Frei Otto's notion of 'minimal structures' (Roland 1972) and Heinz Isler's 'hanging cloth reversed' technique (Chilton and Isler 2000).

\section{Conceiving}

The series Canoe (Fig. 1) and Kayak (Fig. 2) form the starting point for this inquiry. These works juxtapose the smooth tranquillity of the path lines of a lone canoeist and kayaker against rugged landscapes.

Using different photographic techniques in combination with analogue and digital modelling, three processes were devised as ways of generating three-dimensional sculptural forms based on these starting points. The methods underpinning these processes have differing levels of dimensional and spatial precision (Table 1). 


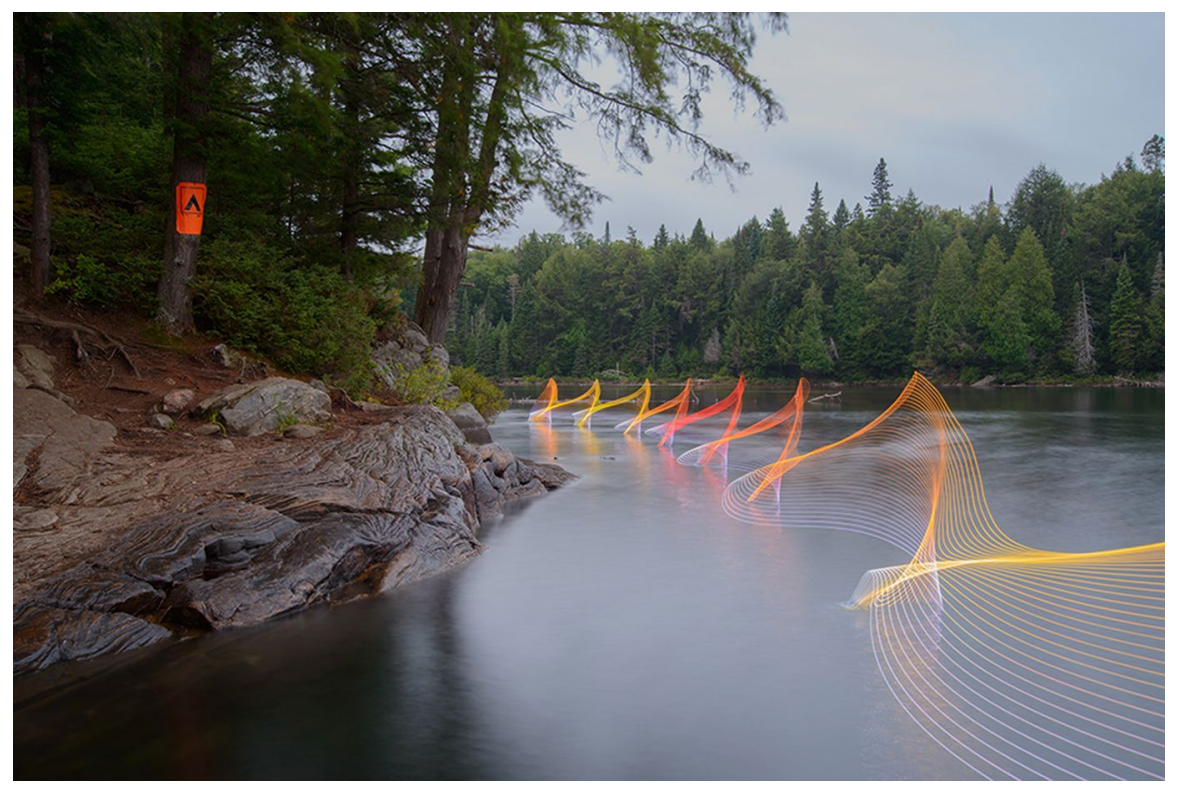

Fig. 1 Algonquin Park-Hambone Lake Canoe I, 2015 (Stephen Orlando)

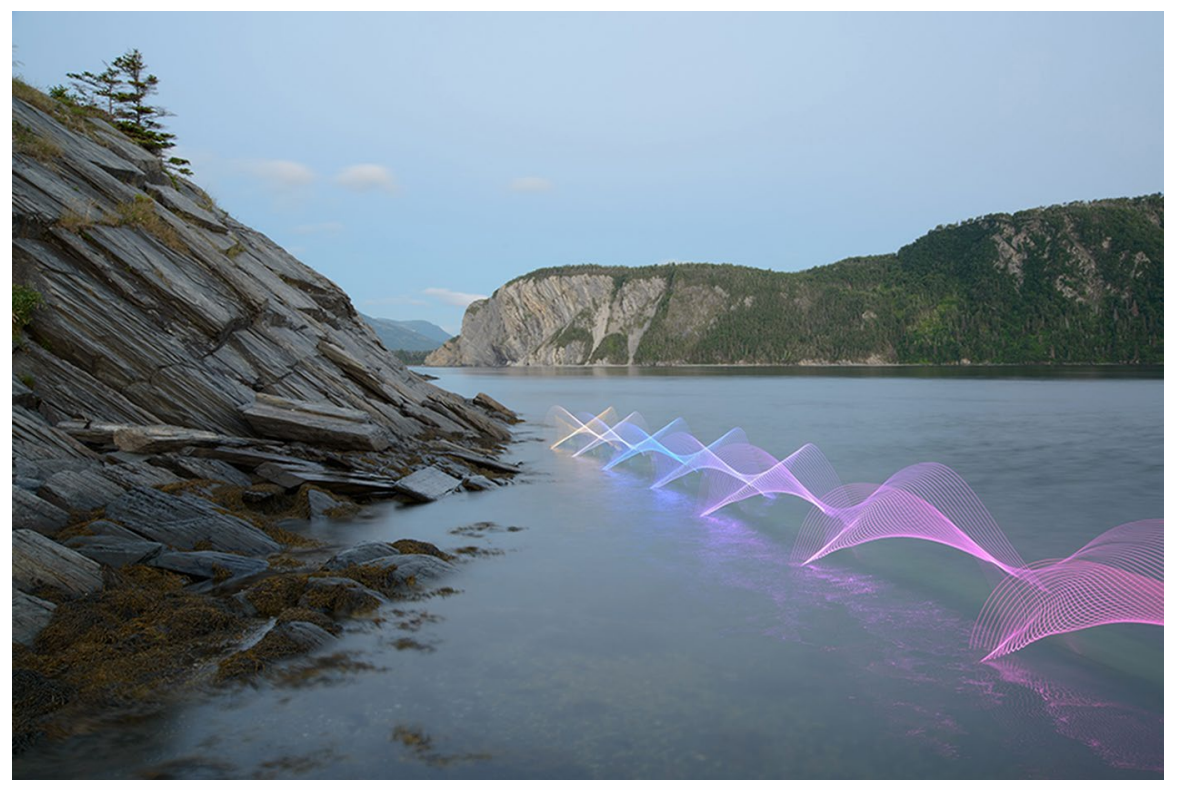

Fig. 2 Gros Morne-Kayak I, 2015 (Stephen Orlando) 
Table 1 Processes for developing sculptural form

\begin{tabular}{lllll}
\hline & Process & Technique & Methodology & Precision \\
\hline I & Interpretation & Geometrically-derived & Analogue & Abstract \\
II & Interpolation & Lofted Keyframes & $\downarrow$ & $\downarrow$ \\
III & Extraction & Point Cloud & Digital & Measured \\
\hline
\end{tabular}

\section{Defining}

\section{Interpretation: Geometrically-Derived}

The simplest geometrically-derived interpretation of the Kayak Motion Exposure images starts with a Platonic form: a circular cone (Fig. 3a). Defined by a series of straight line segments projecting from a circular base, converging at a single point each segment is analogous to the kayaker's paddle and is dimensioned accordingly. A series of these cones are arranged linearly, then mirrored and offset (Fig. 3b). This interlocking aggregation of cones is bisected at its mid-point by a horizontal plane, representing the water's surface (Fig. 3c). The Motion Exposure images invite us to read the action of paddling as a continuous thin 'surface' as opposed to a set of solid forms: removing extraneous faces turns the geometry into a series of conical shells, heightening this sense (Fig. 3d).

The form is underpinned by a certain dimensional precision, but a number of necessary formal simplifications predominate. The most noteworthy of several such 'liberties' is that a true kayaking paddling action does not start and stop at the water's surface as this form suggests. This 'truth' however is also not present in the source image, which describes a fluid unbroken motion across the water's surface. Here then, by implying a datum in this way, the effect is that the geometric surface's visual continuity, while 'inaccurate', remains consistent with the source material.

\section{Interpolation: Lofted Keyframes}

This process starts with the capture of a series of 'keyframe' images of a kayaker paddling. Sequences of images were shot simultaneously by two photographers, one positioned head-on to the kayaker, the second sideways. When shooting stills in photographic 'bursts' with consumer-grade cameras it proved difficult to
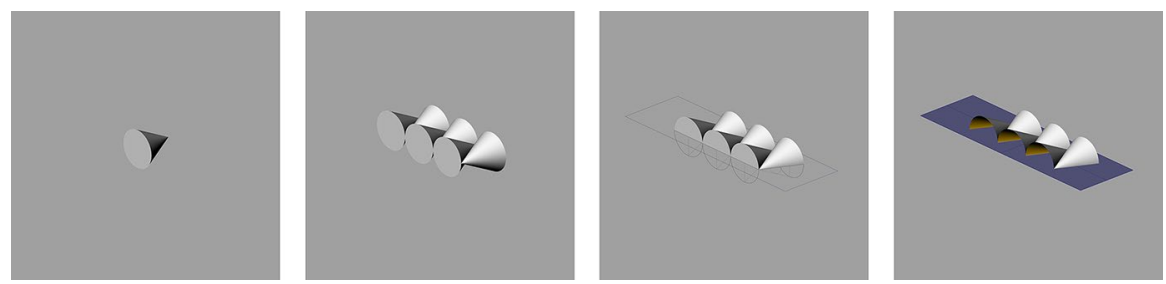

Fig. 3 a-d Geometrically-derived form iterations 
precisely synchronise the two sets of information, a difficulty further exacerbated by a processing lag that occurs for bursts of two seconds or longer.

The same cameras' video capture capabilities proved more fruitful. Positioned as previously and shooting at 24 frames per second (fps), an extended paddling sequence was captured. The footage was processed in Adobe Premiere-a timeline-based video editing application-to extract a series of keyframes as stills.

Video analysis revealed the kayaker paddling at close to 60 strokes/second. The start points of the two sets of video were synchronised with keyframes extracted at quarter-second intervals (every sixth keyframe). Minor fluctuations in the kayaker's stroke rate were compensated for by manually overriding the extracted keyframe by \pm 1 so that the relationship between paddle and water remains consistent stroke-to-stroke (Fig. 4). This decision results in a more idealised form of the action observed as modelled.

The selected keyframes were merged using Adobe Photoshop-an industry standard raster graphic editor software-to form a pair of composite multipleexposure images (Figs. 5, 6) similar to the chronophotographs of Marey. Using known dimensional information (e.g., lengths of paddle and kayak) close approximations of the paddle position can be placed at scale within threedimensional space using Rhino 3D digital modelling software. A process of 'lofting' was then applied, generating a curved surface by interpolating between the fixed points of data established by the 'paddle' positions. Comparison with the Motion Exposure images shows the resemblance of lofted form and original artwork (Fig. 7).

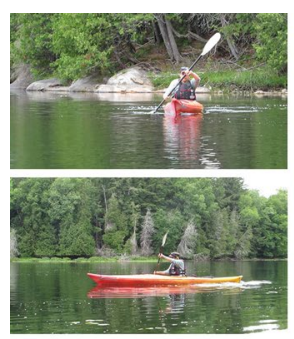

00_00_02_16
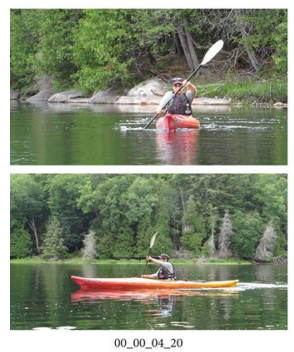

00_00_04_20
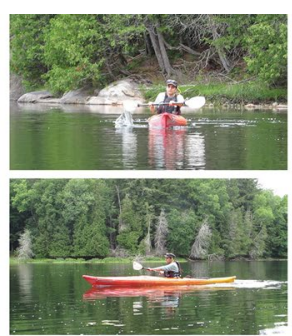

00_00_03_05
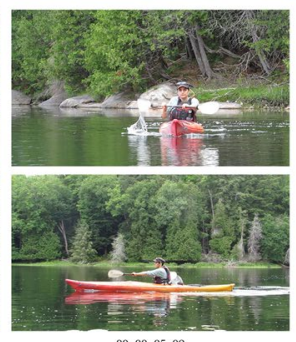

00_00_05_09
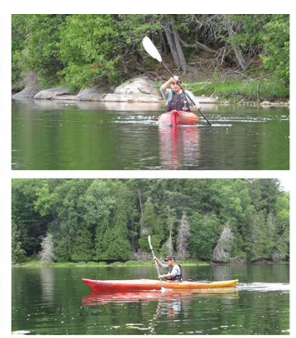

00_00_03_18
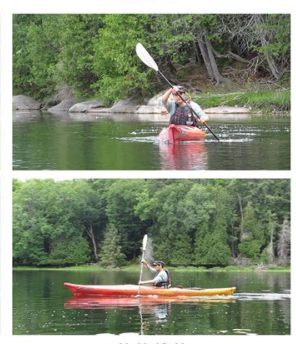

00_00_05_22
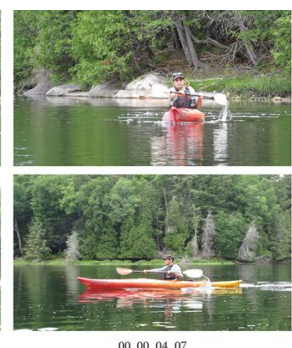

00_00_04_07
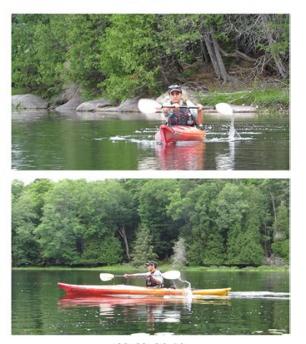

00_00_06_10

Fig. 4 Extracted keyframes 


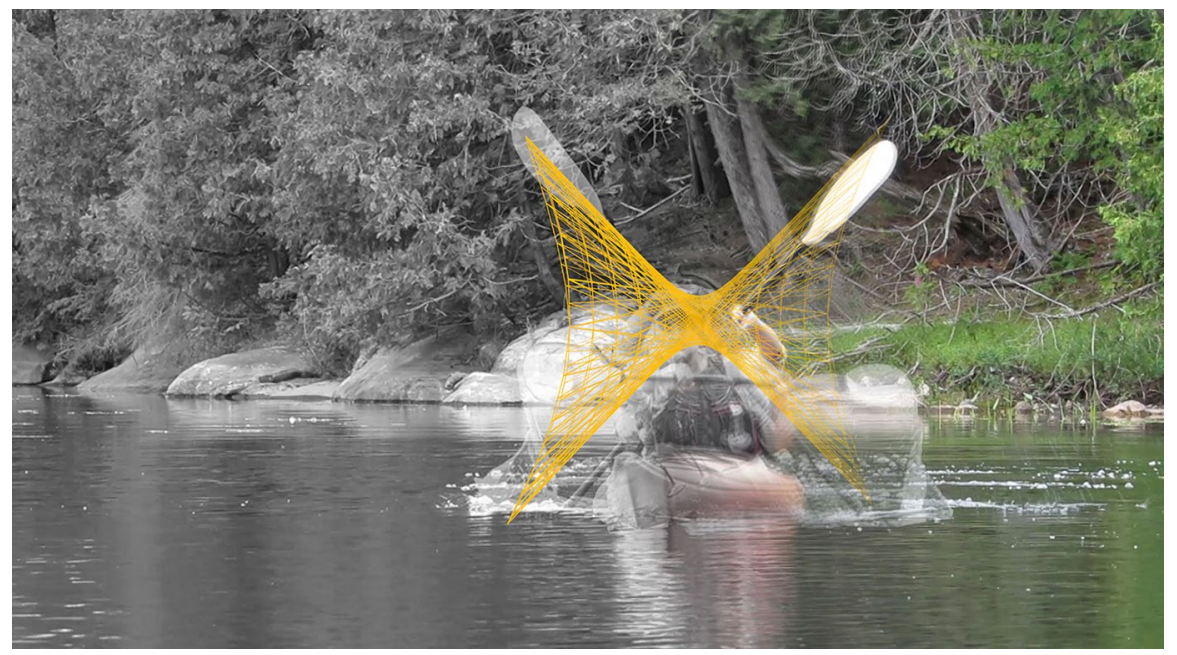

Fig. 5 Composite of keyframes and digital model: front

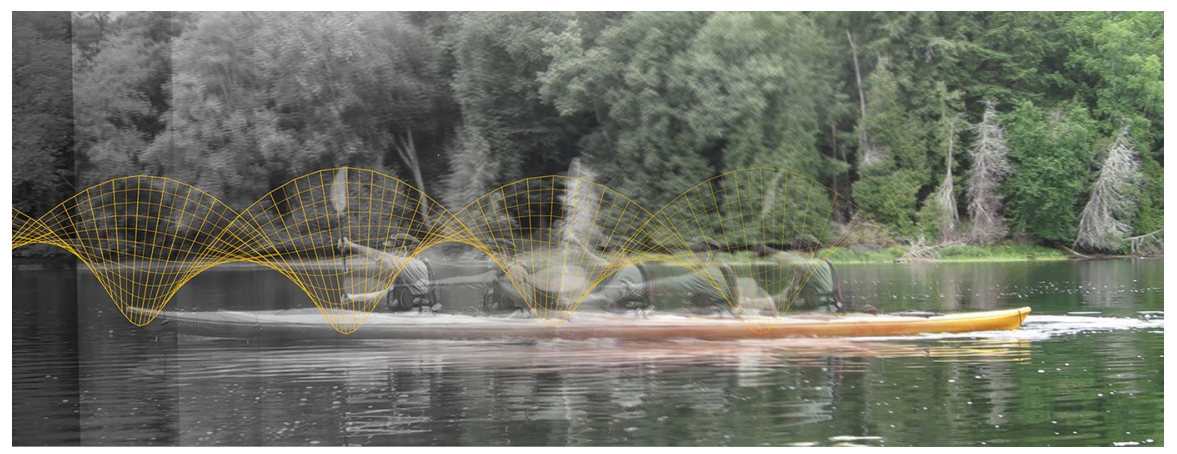

Fig. 6 Composite of keyframes and digital model: profile

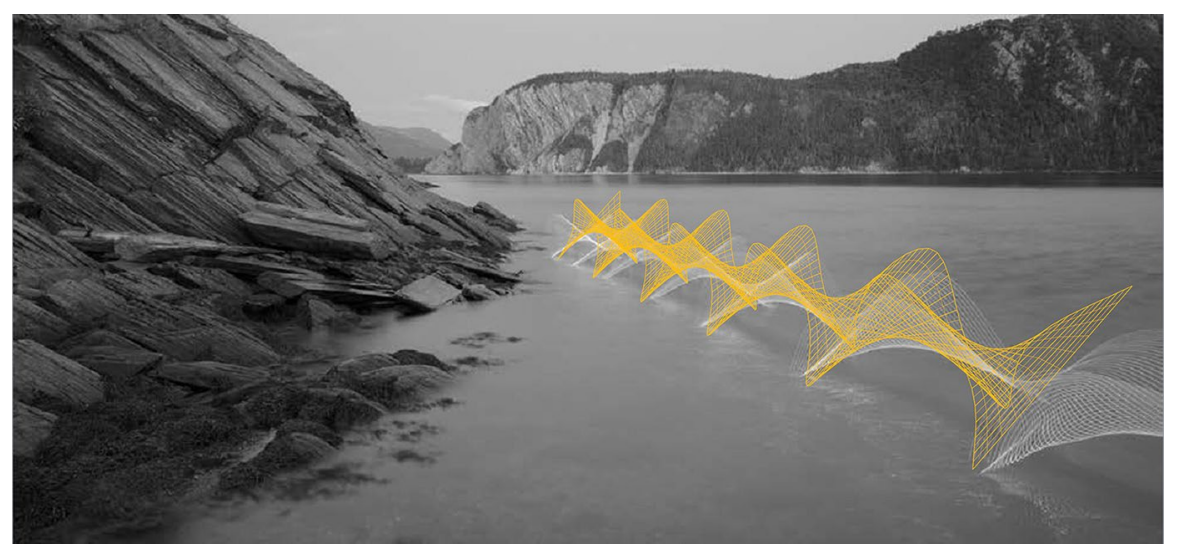

Fig. 7 Composite of digital model and Motion Exposure 


\section{Extraction: Point Cloud Data}

The Extraction process corresponds with the canoe photos in Orlando's photographic series, thus broadening the design investigation. In order to locate the 3D spatial coordinates of the path of the canoe paddle (i.e., point cloud data) an orthogonal stereo camera system was used. The authors acknowledge the fact that more sophisticated motion capture systems exist, however this method was chosen because of its simplicity and low cost. The paddler stood on a box so they could 'canoe' without the paddle hitting the ground. One camera was positioned on a tripod ca. $20 \mathrm{~m}$. in front of the paddler facing them head on and the second on a tripod ca. $20 \mathrm{~m}$. to their right, that is, positioned so its optical axis was $90^{\circ}$ to the first camera (Fig. 8). Both cameras used long focal lengths of approximately $200 \mathrm{~mm}$. so the paddler would fill the field of view. The large $20 \mathrm{~m}$. separation between the camera and paddler reduces the foreshortening of the paddler. This means that the paddle doesn't significantly change in size as it moves closer to and farther from the camera.

The coordinate frame was set up so that the origin was at the feet of the paddler, the positive $y$ axis was the upward direction, the positive $z$ axis was the direction the paddler faced, and the positive $x$ axis was the direction the paddler's right side faced. Therefore, the camera in front of the paddler captured the $x-y$ plane and the camera on the side captured the $y-z$ plane.

Colour-changing LED lights were attached to the paddle, one at the bottom, one at the top. The lights were programmed to pulse at intervals of $51 \mathrm{~ms}$ and the pulses were in a repeating series of six colours (red, orange, yellow, green, blue, pink). Simultaneous long exposure photos were taken with the lights pulsing as the paddler performed one stroke. Images without the paddler were also taken with a vertical pole of known length in the paddler's position. This pole was used to calculate a
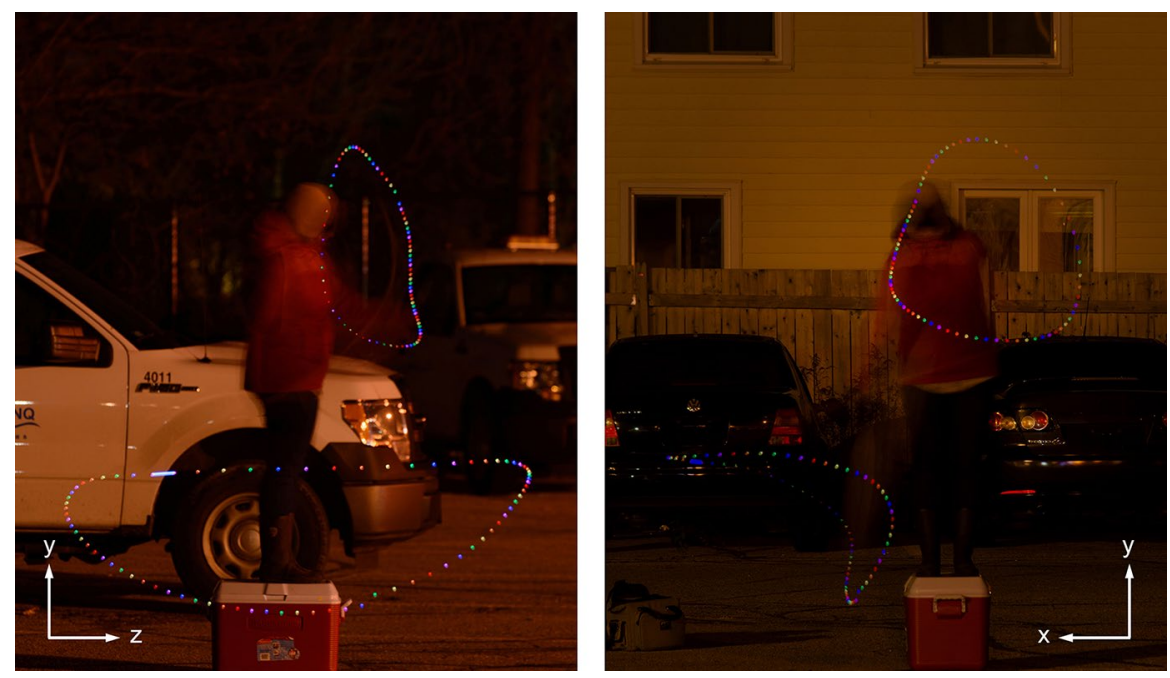

Fig. 8 Point cloud data capture set up 
pixels-per-millimetre scale factor for each camera. The pixel coordinates for each pulse on both images were retrieved manually with an image analysis program (MATLAB). The changing colours simplified identification of the same light pulses across the two images. Using the scale factor, the pulse coordinates were converted to real-world coordinates. The front camera captures the $x$ and $y$ coordinates and the side camera captures the $y$ and $z$ coordinates.

Converting the $x, y$, and $z$ coordinates of the stationary paddler to a moving paddler required adding a time-based offset to each of the $z$ coordinates. For this it was assumed that both the paddler and canoe move at a constant $5 \mathrm{~km} / \mathrm{h}$ in the absolute frame (an average speed for a recreational canoeist). In reality the speed of the canoe varies slightly during the paddle stroke, but this effect was deemed to be negligible for the purposes of this measurement. Since there are $\Delta t=5 \mathrm{~ms}$ between pulses and the $z$ direction speed of the canoe is assumed to be $v=5 \mathrm{~km} / \mathrm{h}$, an offset of $\Delta z=\Delta t v=71 \mathrm{~mm}$, needs to be added to the $\mathrm{z}$ coordinate of successive pulses. More specifically all $z$ coordinates are defined by the following equation, where $i$ is the pulse index starting at zero:

$$
z_{\text {moving }, i}=z_{\text {stationary, } i}+\Delta t v i
$$

Rhino 3D was used to visualise the point cloud data. Seven additional strings of coordinates were created at regular intervals between those originally captured. Each string was assigned a unique colour and the points in each string were connected sequentially to create a series of individually coloured streams (Fig. 9a). Here, a 'sweep' function that 'fits a surface through a series of profile curves that define the surface shape and two curves that define the surface edges' (McNeel 2016) was required to generate a surface (Fig. 9b).

Notwithstanding the obvious formal consequences of the subject matter being a canoeist rather than kayaker, the resulting sculptural figure provides a virtual facsimile of the forms in the original artwork (Fig. 1), both figuratively and dimensionally. The level of fidelity far exceeds that of either of the previous processes tested.

\section{Testing}

These processes result in outcomes that are abstract figures which offer no assurance they could be physically realised. To do so, structural and material

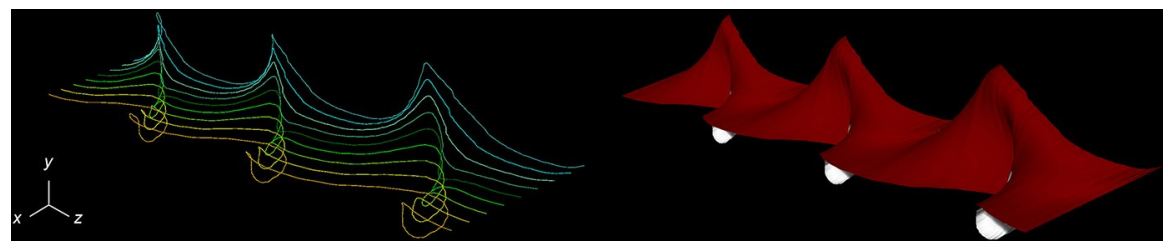

Fig. 9 a, b Point cloud streams and thin-surface form 
strategies must be developed. In accordance with the original artistic intentions, the following criteria were developed:

- The forms must be freestanding

- Structure should be integral to form

- Forms should be of minimal thickness and maintain a sense of fluidity

- The structure should be capable of resisting dead loads (i.e., the structure's own weight) and some environmental loads

- Materials and construction methods must be economical and relatively lowskilled

These resonate with Frei Otto's theory of minimal structures, which has been summarised as 'an attempt to achieve, through maximum efficiency of structure and materials, optimum utilization of the available construction energy' (Otto and Glaeser 1972: 10). Otto's work gave physical form to these ideas through a series of surface structures: constructions whose 'structurally effective volume is relatively large in two dimensions and relatively small in the third dimension' (Roland 1972: 9), this 'third dimension' typically being a structure's thickness. Surface structures therefore offered a natural starting point.

As Otto developed his theory of minimal structures, great strides were being made in two particular types of surface structure: shells and tensile membranes. Otto's preference was for the latter. Through the lens of his own theory, this is easily rationalised:

"Constructional energy" primarily comprises the consumption of material (expressed in terms of weight, volume, cost) and of labour (number of manhours for manufacture and erection). The economy of the structure can be expressed by the ratio of total consumption to performance. According to this definition, minimal structures are also the most economical structures. From this it furthermore follows that low material consumption (e.g., in "lightweight" structures) does not in itself necessarily result in a high degree of economy if, for instance, reduced material consumption is offset by increased labour (Roland 1972: 4).

Indeed Otto's preference prevailed more widely, as Chilton describes in terms that chime with the concern that 'constructional energy' embodies labour as well as materials:

Since the 1970s the use of reinforced concrete shells has declined in developed countries ... due to several factors. One reason is that, traditionally, shell construction is labour intensive, which makes it expensive in high wage economies. ... Further, the high cost of the formwork and falsework required to produce shell forms (which is often used only once or a limited number of times) has also reduced their acceptability (Chilton and Isler 2000: 12).

Considered in relation to the figurative forms and aspirations described here, this introduces an interesting tension. The 'thinness' of surface structures 
commends them above any other structural type, however tensile membranes, and in particular the mast-and-cable-supported membranes most favoured by Otto, rely on peripheral structural elements somewhat separate to their form. By contrast, structure is integral to the form of thin shells. However, due to the labour and formwork/falsework requirements these are intensive in terms of 'constructional energy'.

Seeking to reconcile these challenges, we turned to the work of master shell designer Heinz Isler. In his seminal paper 'New Shapes for Shells' (Isler 1959), he identified a form-finding technique termed as the 'hanging cloth reversed' method, stating that it is 'for three-dimensional problems, what the catenary line is for two-dimensional arches' (Chilton and Isler 2000: 17). This alludes to Robert Hooke's observation in 1676 'Ut pendet continuum flexile, sic stabit contiguum rigidum inversum' ("As hangs the flexible line, so but inverted will stand the rigid arch") (Heyman 1998: 79). Isler demonstrated this principle with an illustration of an inverted frozen hanging cloth measuring $3 \times 3 \mathrm{~m}$., yet less than $1 \mathrm{~mm}$ thick - one of a number of such 'playful experiments' made by Isler over the course of his life (Chilton and Isler 2000: 38). This technique would prove productive numerous times over Isler's career, although was largely confined to form-finding models and not intended for final structures, for like many of his contemporaries, Isler was principally concerned with exploiting the incredible structural capabilities of shells to create medium- and large-span structures. As Chilton observes:

Reinforced concrete shell structures directly formed with fabric are generally considered feasible at the small scale. However, due to handling difficulties the usual method of construction, involving inversion of material cast on a hanging form suspended under tension is generally not feasible at the scale of Isler's shells (Chilton 2012: 90).

Flow, however, is interested in the formal and aesthetic potential of thin-shell structures, not maximising span. Might it therefore be possible to consider the envisaged structure as though it were one of Isler's models? If so, can the 'hanging cloth reversed' technique address the challenge of reducing 'constructional energy' such that small-span shells could become minimal structures?

Surface analysis enables forms to be understood as co-planar, or as singly or doubly curved. It also enables us to determine whether any curvature is towards the same side of the surface in all directions (synclastic) or opposing sides (anticlastic). Although visual inspection is often adequate, digital analysis is invariably more nuanced and accurate. False colour mapping was assigned to the generated surface forms to assist the identification of positive (synclastic), negative (anticlastic) or zero Gaussian curvature (Fig. 10).

This is of particular use when considering the 'hanging cloth reversed' technique, as only surfaces with zero Gaussian curvature are developable surfaces (i.e., can be flattened onto a plane without distortion). As one might imagine of surfaces described by a straight paddle, all the forms although curved are underpinned by various configurations of straight lines. However, only the geometrically-derived form exhibits zero Gaussian curvature that makes it developable. 

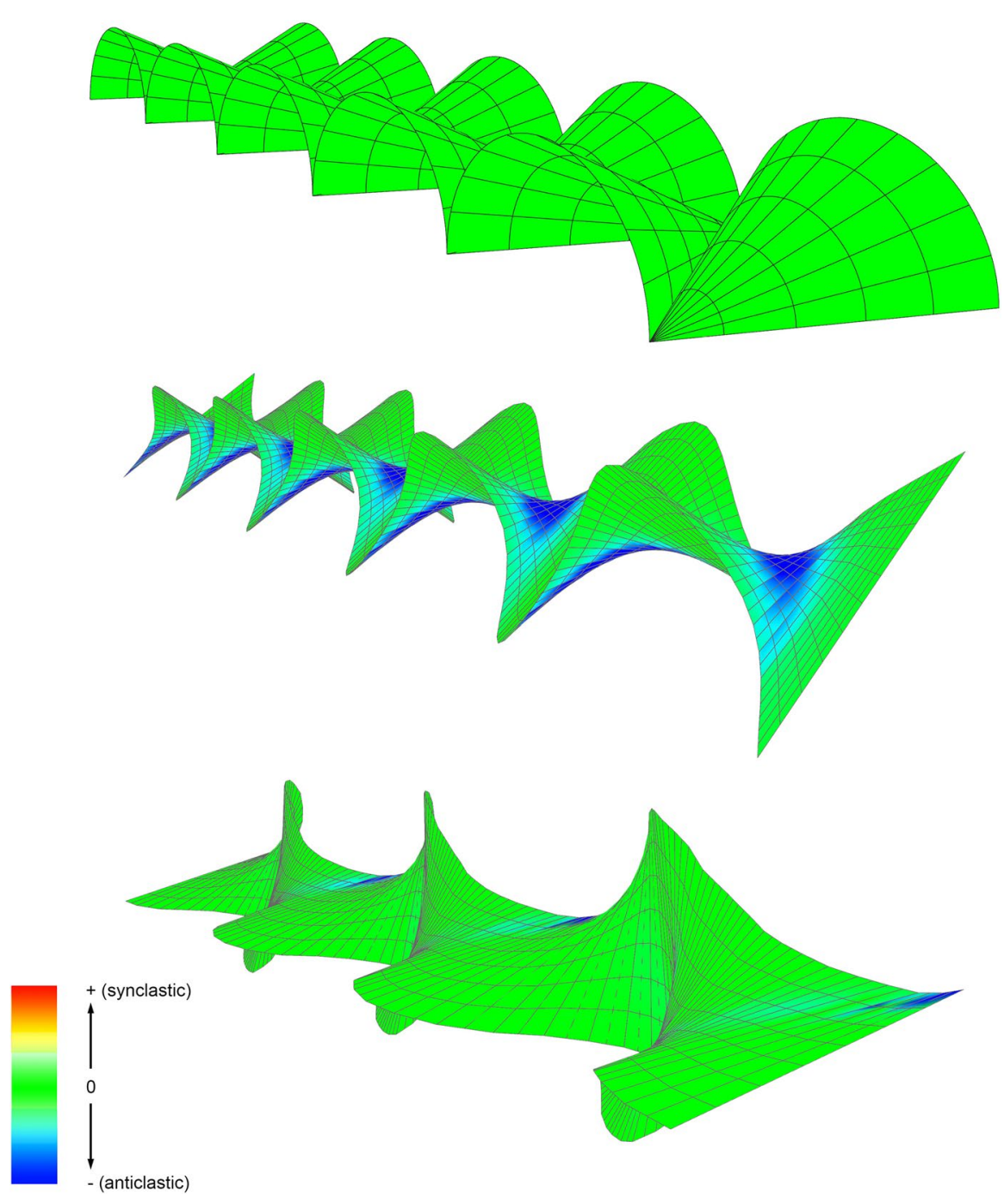

Fig. 10 Surface curvature analysis

\section{Developable Surface}

The underlying geometry of a bisected right circular cone is a circular sector. For the geometrically-derived model, the angle of the sector is $90^{\circ}$, giving a quadrant (Fig. 11a). Depending upon the desired curvature of the developed surface, this central angle can be varied. Once developed this quadrant gives a single forwardpaddling stroke. The quadrant is mirrored and tessellated ad infinitum, providing the resulting form is to suggest linear motion (Fig. 11b). Non-linear movement could be implied by adjoining circular sectors of unequal angles. Depending on scale, and 


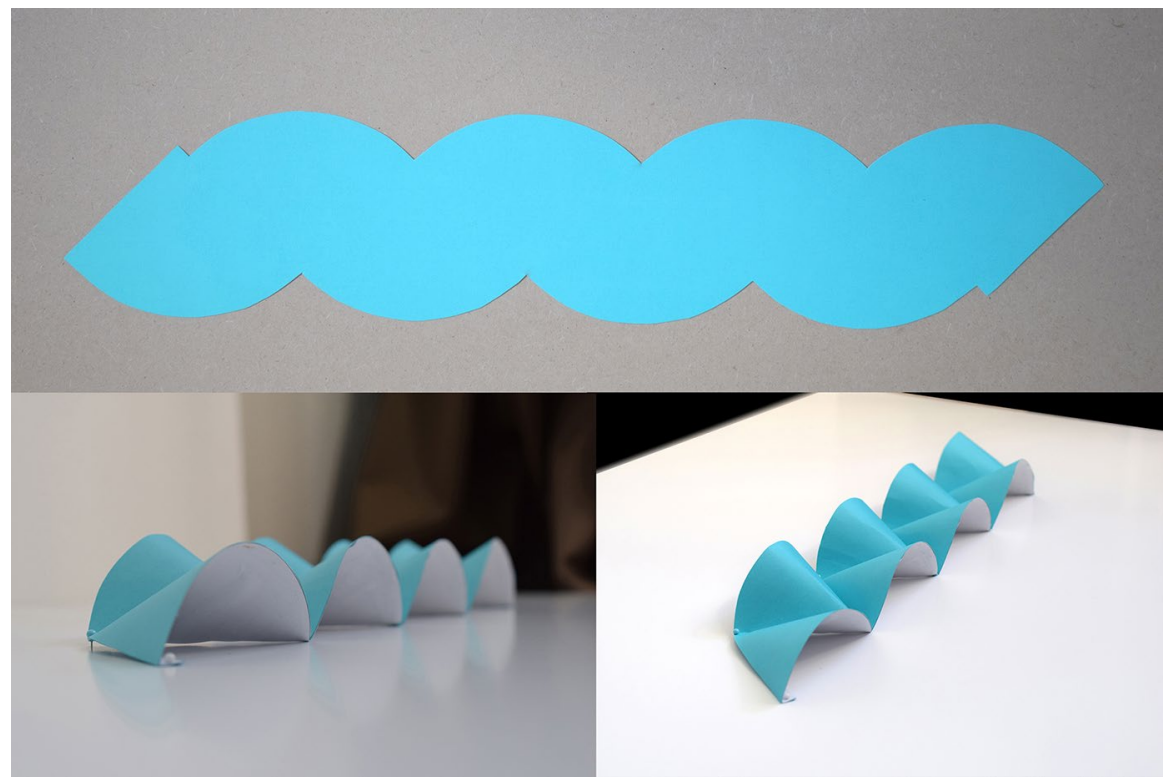

Fig. 11 a-c Geometrically-derived shell, developable surface: first iteration

acuteness of angles, this may result in an overall shape that is non-developable as although each module is developable, the composite sequence may become akin to a helix. This may be addressed by joining together one or more arrays cut separately.

The developable surface geometry is further modified to better approximate the Motion Exposure images. Firstly, the outer edge of each segment pitches outwards in a manner that calls to mind works such as Candela's classic design for Los Manantiales Restaurant, Xochimilco, Mexico City, of 1958. This is achieved by adjusting each quadrant's arc so that it is no longer formed by a constant radius (Fig. 12b).

Next, the undulating perimeter edge condition suggested by the Motion Exposure images is intimated by further adjustments to this arc. Here, the adjustments take the form of a gentle sigmoidal (i.e., S-shaped) curve retaining a reflected symmetry around each vault's centre-line (Fig. 12c).

Finally, the spatial continuity of Isler's freeform shells is introduced. An arc is subtracted from each circular sector's enclosing radii. The sector is notionally divided into $30^{\circ}$ segments, with the arcs contained wholly within their respective thirds to ensure structural continuity (Fig. 12d). Repeated, this creates a series of vesica piscis (pointed ellipses) holes, the internal free edges of which are connected along their full length with their neighbour (Fig. 13). These holes are inset such that reasonable contact with the ground is maintained for load transferral. 


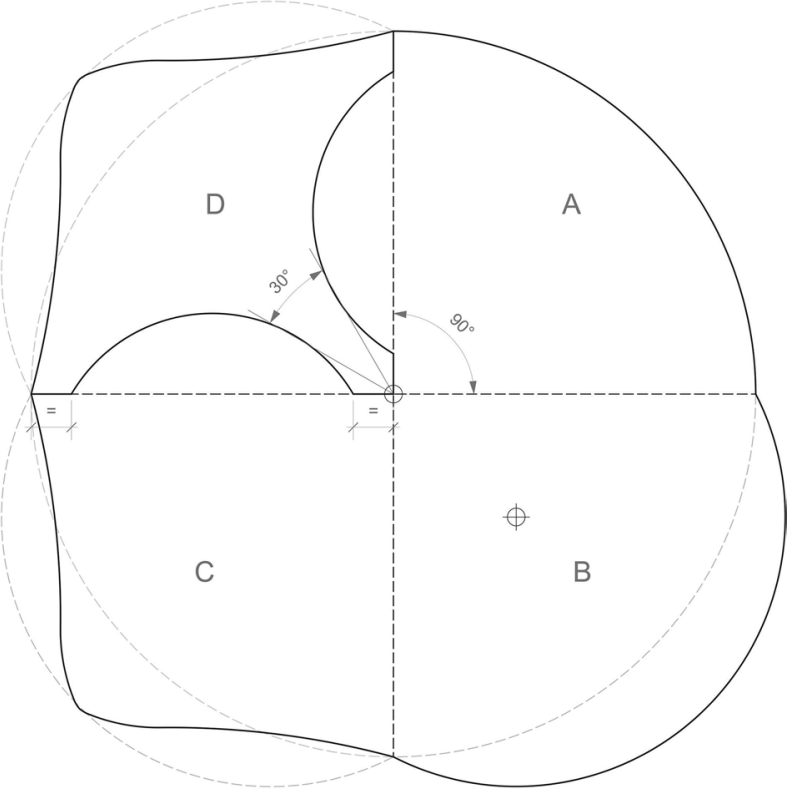

Fig. 12 a-d Geometrically-derived shell, iterative development composite drawing

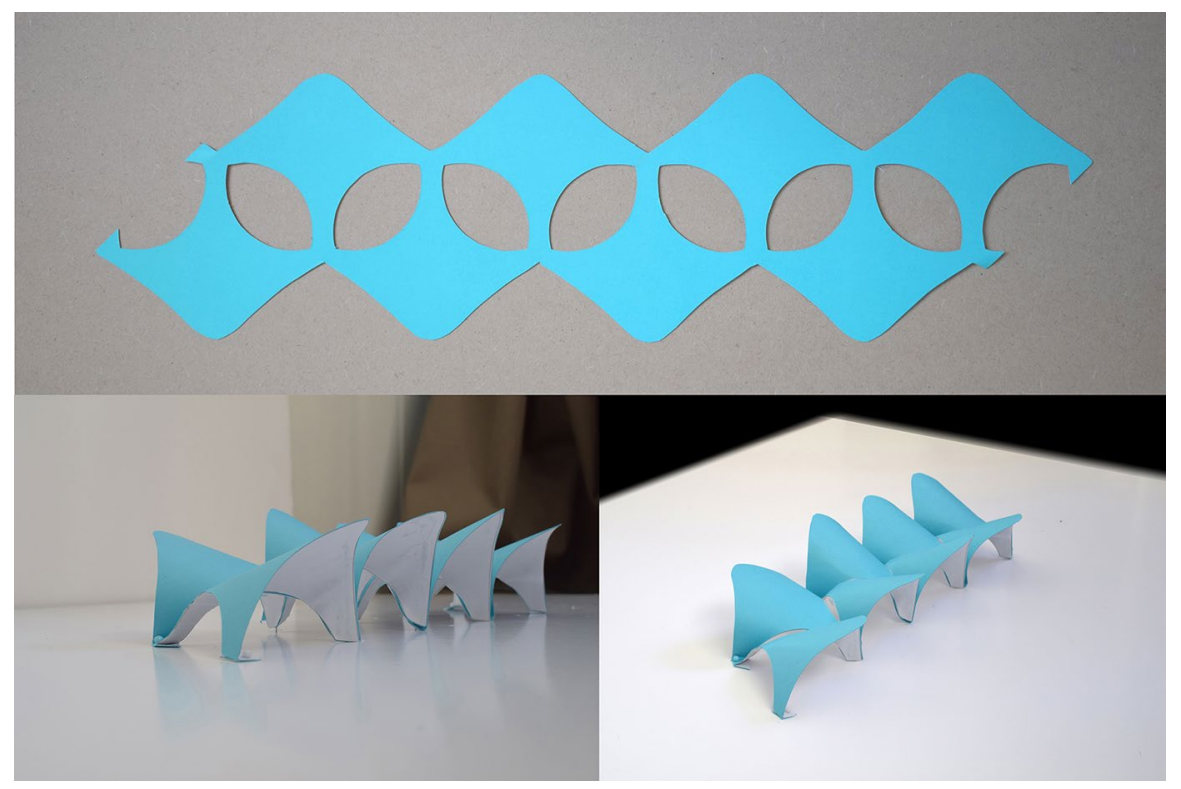

Fig. 13 Geometrically-derived shell, developable surface: fourth iteration 

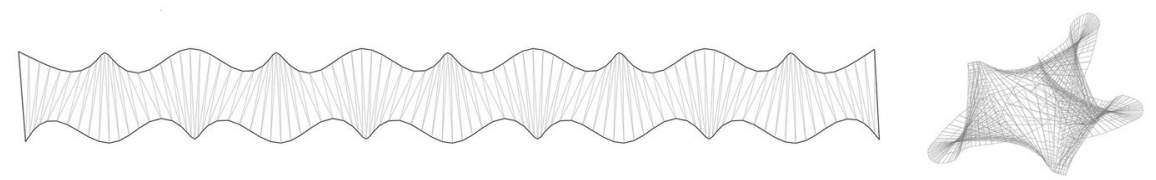

Fig. 14 a, b Approximated flattened forms

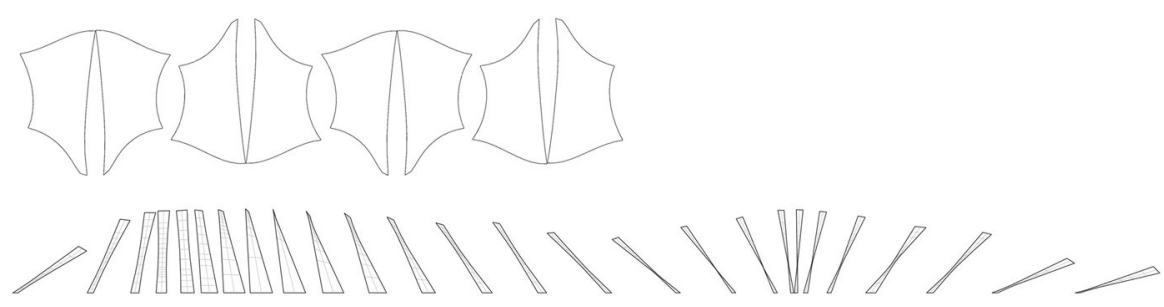

Fig. 15 a, b Panellised cutting patterns

\section{Non-developable Surfaces}

Any attempt to flatten forms with non-zero Gaussian curvature onto a plane - as is necessary for the hanging cloth reversed method - would result in stretching or tearing. This issue is not insurmountable if the resultant stretching or tearing is anticipated and controlled. The forms generated by the Interpolation and Extraction processes were analysed as having anticlastic curvature and are therefore nondevelopable. Rhino 3D software roughly approximates their two-dimensional flattened shapes, resulting in one fairly cohesive linear shape (Lofted Keyframes model-Fig. 14a), albeit with none of the fissures or tears necessary to create double curvature, and one incredibly complex, almost illegible shape (Point Cloud model-Fig. 14b).

This variance can partly be accounted for by the difference in paddling motion of kayaker and canoeist, but also by the simplification occurring from using a notional 'water surface' as a cutting plane. Anticlastic curvature aside, the Lofted Keyframe model which has been 'edited' in this way poses no further complexity. Conversely, the Point Cloud model reveals the motion both above and below the water's surface, resulting in a surface that not only self-intersects, but does so at the point of most acute curvature.

Although envisaged as a 'proper' shell in pure compression, the 'hanging cloth reversed' method is predicated on forms initially in pure tension. The process of flattening the respective forms was repeated using a software designed to generate panellised cutting patterns for the construction of tensile fabric structures while minimising distortion by optimising orientation and spacing of seam lines (MPanel). It is instructive to compare the outcomes of this process for both the relative size and number of unique panels derived from the Lofted Keyframe (Fig. 15a) and Point Cloud (Fig. 15b) models respectively. 
Seams are one of the most technically complex aspects of any fabric structure, not least the problem of maintaining alignment when joining curves of opposing directions. They pose a conundrum for designers: more panels theoretically helps minimise distortion but increases fabrication complexity. Mindful of the aspirations to minimise cost, 'constructional energy', and enable realization with relatively low-skill labour, the highly-panellised Point Cloud solution is immediately compromised. This is not necessarily an outright rejection of the Point Cloud method: the canoeist's stroke has more sectional variation along its length than that of the kayakers, so irrespective of how the form was derived it would invariably be more complex. The greater fidelity of this method, however, inherently results in greater formal complexity than the more approximated methods.

\section{Convincing}

Study models made of the derived patterns cut from cotton fabric and fixed by polyurethane resin proved inconclusive. Although constructed at what might be considered a relatively large scale for an architectural model (1:10), some of the difficulties are related to what thin-shell designer Eduardo Torroja referred to as the 'law of scale' when discussing his mixed views towards models. Torroja's reservations stemmed from the difficulties of modelling using materials that behave in a similar way to those intended for the final construction and the complications of scale when working with spans of 500 or 700 times the thickness (Fernández Ordóñez and Navarro Vera 1999). Despite the study models constructed here being fabricated from the same material as imagined at full scale, the 'law of scale' also presents difficulties for fabric: weave, density and seams that are difficult to scale proportionately, all conspire against the theoretical forms anticipated being assumed when the structure is hung (Fig. 16): evidently further extending the observation that 'It is a little known paradox of textile structure design that smaller structures are, in general, more difficult to pattern than larger ones' (Gründig 2000: 11).

Torroja had full confidence in calculation as proof, reasoning that the engineer has no choice but to accept the complexity of the calculations ...' (Fernández Ordóñez and Navarro Vera 1999: 73). Not all shell designers shared this conviction. Candela and Isler, both of whom can also be considered to have
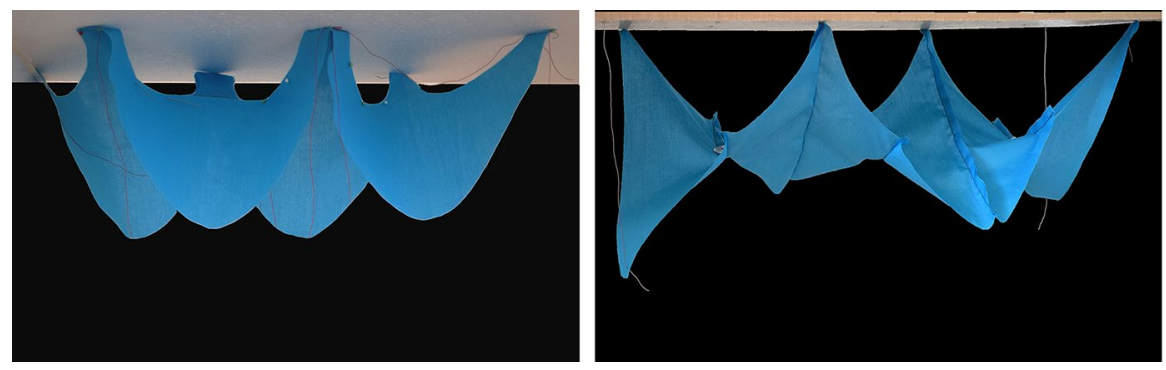

Fig. 16 Hanging cloth reversed fabric models - 1:10 scale 
created works of structural art using thin-shells, were more reserved. Candela opined that

all calculations, no matter how sophisticated or complex, cannot be more that [sic] rough approximations of the natural phenomenon they try to represent by means of a mathematical model (Billington et al. 1973: 126).

Isler believed that

the building itself is something absolutely different, new and unique ... its behaviour depends on the quality of design and the quality of concrete; it depends on the temperature when poured; it depends on the construction sequence; it depends on the age; it depends on everything... (Chilton and Isler 2000: 23).

Candela and Isler treated physical models as sacrosanct in combatting the limitations they perceived of computational processes. Often working at large, and even full, scale, their motivation was not limited to conceiving and testing novel structural forms, but also the means of construction. It is this holistic approach which distinguishes structural artists from engineers, for 'a work of structural art is always the product of one person's imagination, an individual who conceives a new form, visualizes its final appearance, defines it by calculations, and develops a means of building it' (Billington and Moreyra Garlock 2010: 340). Others, including Eladio Dieste (Anderson and Dieste 2004) and Rafael Guastavino (Ochsendorf and Freeman 2010) similarly followed this holistic approach, for as Candela remarked 'the only way to be an artist in this difficult specialty of building is to be your own contractor...' (Garlock et al. 2008: 180).

Having conceived a form, visualized it and defined it by (geometric) calculation, for Flow to be convincing it was necessary to also develop a means to build it. Sheil defines prototypes as

an enterprise that takes risks - one of which is to challenge all those involved to see how the part they need to (or indeed could) play in the game should change. Prototypes that simply reaffirm an assertion have a role, of course, but those that provoke a significant rethink are considerably more powerful (Burry and Burry 2016: 8-9).

Testing fabric-based structures at larger scales can diminish the issues encountered by the 'law of scale', but does not de facto challenge 'assertions'. Challenging oneself to define and test the construction method, however, provokes a 'significant rethink' and arguably distinguishes the enterprise of prototyping from that of model making.

For prototyping Flow, it was useful once again to look to Isler. Borrowing his idea of freezing water as the means of fixing the fabric form not only accords with the aspiration that structural art (and minimal structures) should be economic, but also that it should be efficient in the sense that (depending on context) doing it makes use of an inert abundant natural resource that is locally available. Diminishing the environmental impact of construction activities at every stage-including 
prototyping-should be a primary consideration for all designers: so much so that perhaps it should become the fourth ideal of structural art.

Beyond a chapter that describes some general principles in Chilton's authoritative monograph on Isler's work, there is little information available that reveals how Isler addressed the challenges encountered from this unusual form of construction, which he referred to as 'playful experiments' (Chilton and Isler 2000: 38). This part of the investigation therefore sought to (re)discover solutions for these challenges, and several novel conditions arising from the design including:

- Construction of a geometrically-derived ice-shell

- Transposition of fabric pattern-making techniques to thin-shell construction

- Employing fabric-lamination as both aesthetic and structural device

- Allied to the above, using tailoring techniques (e.g., concealed seams) as a method of architectural detailing

- Development of construction methods to minimise exposure to extreme environment.

The site for construction is a wooded hillside in the Canadian wilderness. At the foot of the hill the wood meets the shore of a large lake. The lake is used for recreational activities including kayaking during the summer, before freezing over as temperatures cool. Artistically, the notion of both landscape and activity alike becalmed by the onset of the frigid winter weather was appealing. Practically, the lake offers a perfect isotropic plane for construction and a vast reservoir of water beneath its surface readily available for construction.

Two sets of the geometrically-derived pattern were cut from contrasting coloured cotton fabric (Fig. 17a). These were stitched together and turned inside out in order to conceal the seams (Fig. 17b). Two parallel ratchet lines were strung up between two pairs of mature trees on the banks of the lake (Fig. 17c). The fabric was suspended from the ratchet lines by nylon ropes fixed through the shell's springing
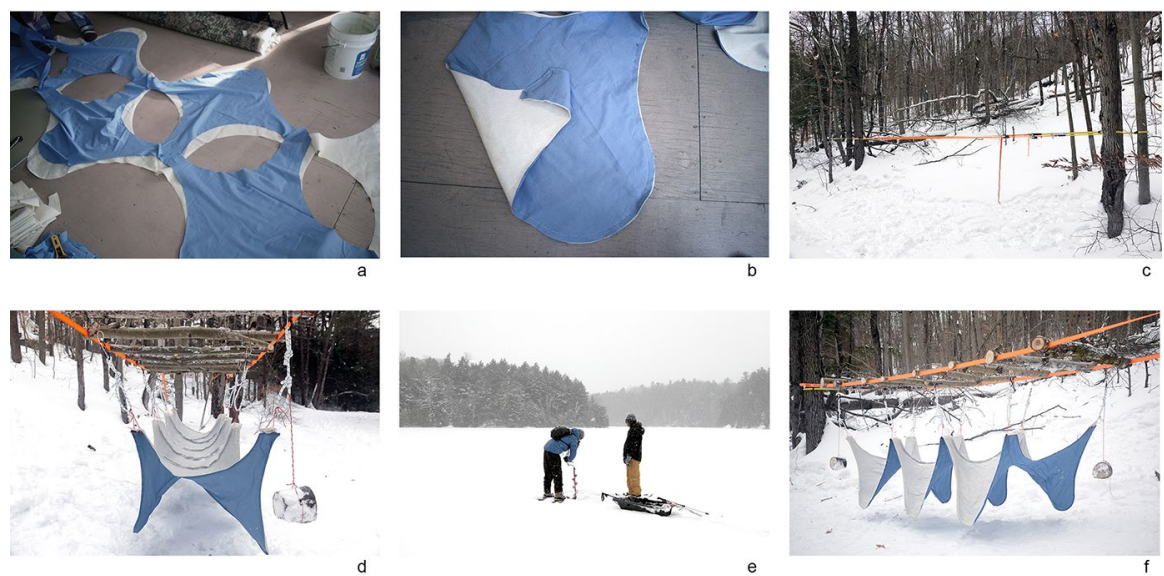

Fig. 17 Flow, construction sequence 
points. The inward pull observed in the smaller test models was counteracted by suspending small logs directly beneath these points (Fig. 17d). Water was extracted from the lake through a hole made using an ice auger (Fig. 17e) and carried to the construction site in a container. The fabric was submerged in the water for a couple of minutes to ensure even saturation before being rehung (Fig. 17f). The ratchet actions allowed the hanging lines to be re-tensioned to counteract the additional load of the water. At an ambient air temperature of $-12^{\circ} \mathrm{C}\left(+/-0.5^{\circ} \mathrm{C}\right)$, equivalent to $-20^{\circ} \mathrm{C}$ with windchill, the fabric froze solid in just $15 \mathrm{~min}$, whereupon it was detached from the ratchet lines, inverted and easily carried to its final position on the lake by four people (Fig. 18).

\section{Discussion}

Modelling may be considered a means to an end and frequently this is so. It can be instructive however to consider modelling as an end in itself. As an artefact, Flow presents an original and novel architectonic form but could, perhaps, be considered esoteric; more so given the quixotic decision to use ice as a construction material. However, when considered as a model of processes to conceive and realise similarly complex and original forms, Flow offers more generalisable outcomes of wider significance.

The first process for consideration is the approaches devised and rigorously tested to record movement ('Defining'), and subsequently transpose these into three-dimensional forms ('Testing'). These alternative approaches reveal an

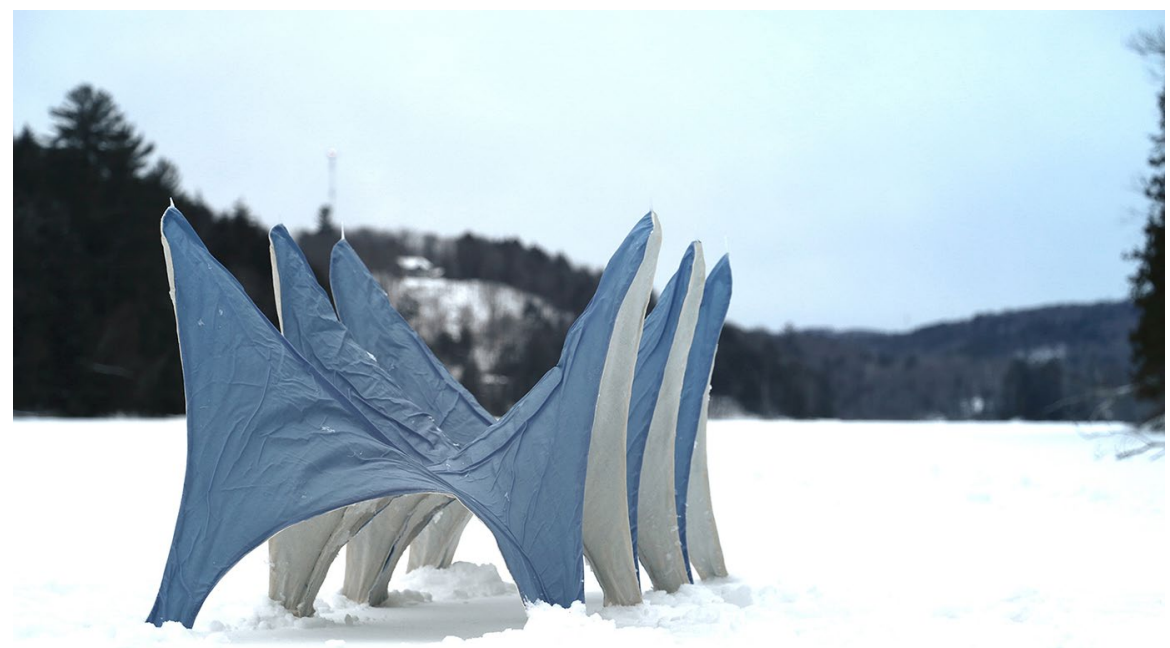

Fig. 18 Flow, Val-des-Monts, Canada, 2019 
interesting tension: digital processes make it increasingly possible to model complex information or data with ever-increasing levels of resolution, however this enhanced fidelity did not necessarily prove advantageous in transposition. Indeed, making these forms structural required a designer with a faculty for abstraction to act as interlocutor.

This is not to dispel the high-fidelity digital approach ('Extraction'). Although more demanding in terms of technique and equipment, it is also the most easily reproducible, in that a similar set-up would assure a consistently similar outcome, albeit one in which the nuanced differences in the actions recorded became apparent. Indeed, making such nuances visibly manifest is one of the most enticing prospects for this methodology. It is ventured that each individuals' actions are distinct and unique: a sort of kinetic 'fingerprint'. This process of recording and visualising allows individual fingerprint to be interrogated further. This presents exciting potential didactic possibilities of potential significance for any form of analytical kinesiology - from refining technique (e.g., sports coaching) to rebuilding technique (e.g., physiotherapy). A paradigm of such innovation is the influence Frank and Lillian Gilbreth's pioneering motion studies had on everything from manufacturing (Price 1989) to surgery (Baumgart and Neuhauser 2009).

The second process of consequence is that of developing the means to build Flow using the hanging cloth reversed method ('Convincing'). This paper has established that although thin-shell structures may accord with many of the precepts of minimal structures and structural art in being (structurally) efficient and elegant, the constructional energy required to build formwork and falsework is both (materially) inefficient and uneconomical (Chilton and Isler 2000). In the mid-twentieth century, renowned structural engineer Pier Luigi Nervi summed the challenge faced by reinforced concrete construction (and ergo shell structures) neatly thus:

Apart from the unconquerable inertia of our own minds, which do not seem to be able to adopt freely any new ideas, the main cause of this delay is a trivial technicality: the need to prepare wooden forms (Nervi et al. 1956: 95).

We continue to wrestle with this problem today, and consequently thin-shell structures have - despite their potential - become largely obsolete.

Viewed as a large-scale model of a shell structure, Flow addresses some of the issues of fabric-based structures alluded to by Torroja's 'law of scale'. Although not yet of occupiable size, Flow demonstrates the 'hanging cloth reversed' method's potential for constructing elegant, formally complex, small-span, fabric-reinforced, thin-shell, structures liberated from the 'trivial technicality' of formwork. The construction process is repeatable, requires no formal construction skills, and Flow proves it to be efficient and economical in every sense implied by 'constructional energy'. Of further note, increasing the scale would have negligible impact upon the constructional energy required to fabricate, hang or fix the form, whether built using ice or another state-change material. This finding is of significance as it revives the idea of thin-shell structures as true minimal structures, presenting interesting possibilities for constructing small-span fabric-based shell structures such as pavilions, temporary structures or emergency shelters with minimal skill, materials and time. 
Acknowledgements All images are by the authors.

Open Access This article is licensed under a Creative Commons Attribution 4.0 International License, which permits use, sharing, adaptation, distribution and reproduction in any medium or format, as long as you give appropriate credit to the original author(s) and the source, provide a link to the Creative Commons licence, and indicate if changes were made. The images or other third party material in this article are included in the article's Creative Commons licence, unless indicated otherwise in a credit line to the material. If material is not included in the article's Creative Commons licence and your intended use is not permitted by statutory regulation or exceeds the permitted use, you will need to obtain permission directly from the copyright holder. To view a copy of this licence, visit http://creativeco mmons.org/licenses/by/4.0/.

\section{References}

Anderson, Stanford and Eladio Dieste. 2004. Eladio Dieste : innovation in structural art. New York: Princeton Architectural Press ; [London : HiMarketing].

Baumgart, A. and D Neuhauser. 2009. Frank and Lillian Gilbreth: scientific management in the operating room: BMJ Publishing Group Ltd.

Billington, David P. 1985. The Tower and the Bridge: The New Art of Structural Engineering. Princetown University Press.

Billington, David P., Robert Maillart, John Fredrick Abel and Robert Mark. 1973. The Maillart Papers: From the Second National Conference on Civil Engineering: History, Heritage and the Humanities: Commemorating the Hundredth Anniversary of the Birth of Robert Maillart, October 4, 5, and 6, 1972, Princeton University. Department of Civil and Geological Engineering, Princeton University.

Billington, David P. and Maria E Moreyra Garlock. 2010. Structural art and the example of Félix Candela. Journal of structural engineering 136 (4):339-342

Burry, Mark and Jane Burry. 2016. Prototyping for architects. Thames and Hudson

Chilton, John. 2012. Form-finding and fabric forming in the work of Heinz Isler. Paper presented at the Proceedings of Second International Conference on Flexible Formwork.

Chilton, John C. and Heinz Isler. 2000. Heinz Isler: the engineer's contribution to contemporary architecture. London: Telford

Fernández Ordóñez, José Antonio and José Ramón Navarro Vera. 1999. Eduardo Torroja: ingeniero. Madrid: Pronaos:240-243.

Garlock, Maria E. Moreyra, David P. Billington, and Princeton University Art Museum. 2008. Félix Candela : engineer, builder, structural artist. Princeton, N.J.New Haven ; London: Princeton University Art Museum ; Yale University Press.

Gründig, L., E. Moncrieff, P. Singer and D. Ströbel. 2000. High-performance cutting pattern generation of architectural textile structures. In Proceedings of International Colloquium on Computation of Shell And Spatial Structures.

Heyman, Jacques. 1998. Structural Analysis: A Historical Approach. Cambridge: Cambridge University Press.

Isler, Heinz. 1959. New Shapes for Shells. Paper presented at the International Association for Shell Structures, Madrid, Spain,

McNeel, Robert \& Associates. 2016. Rhinoceros 5: User's Guide. http://docs.mcneel.com/rhino/5/ help/en-us/index.htm\#commands/sweep2.htm\%3FTocPath\%3DCommands\%7CAlphabetical\% 7CS\%7C__ 184. Accessed 23 May 2021.

Nervi, Pier Luigi, Giuseppina and Mario Salvadori. 1956. Structures. New York: F.W. Dodge

Ochsendorf, John Allen and Michael Freeman. 2010. Guastavino vaulting : the art of structural tile. New York: Princeton Architectural ; Enfield : Publishers Group UK [distributor].

Otto and Glaeser, 1972 Otto, Frei and Ludwig Glaeser. 1972. The Work of Frei Otto. Museum of Modern Art; distributed by New York Graphic Society, Greenwich, Conn

Price, Brian. 1989. Frank and Lillian Gilbreth and the manufacture and marketing of motion study, 1908-1924. Business and economic history: 88-98.

Roland, Conrad. 1972. Frei Otto : Structures. [S.1.]: Longman. 
Publisher's Note Springer Nature remains neutral with regard to jurisdictional claims in published maps and institutional affiliations.

Tim Ingleby is a qualified UK-based architect and Senior Lecturer in architectural design at Northumbria University. With over a decade's experience working with several of the UK's leading young architectural practices he has contributed to a number of built projects, as well as the winning designs in several prominent open international competitions that include a series of innovative pavilion structures. His current practice-based research and teaching continues to develop this interest in contemporary architectural design allied with novel form-finding methods, structural systems and principles of construction and has been included in a number of prominent gallery exhibitions, including most recently the Royal Scottish Academy, Edinburgh and Het Nieuwe Instituut, Rotterdam.

Stephen Orlando is a photographer and aerodynamicist based in Kitchener, Ontario, Canada. During his Engineering studies, he became adept at using high-speed photography to study fluid flow: he now specializes in light painting photography. Stephen draws inspiration for his work from his aerodynamics background as well as his love for the outdoors. An avid canoeist and kayaker, many of his photo shoots take place in remote locations of the Canadian wilderness. It is his aim to create both aesthetically pleasing images as well as show movement which usually goes unseen. His work has been exhibited in Korea, Italy, Taiwan, and at home in Canada. 